\title{
Incidence and types of vaginitis in pregnant women attending routine antenatal care at Tanta University Hospital: a cross-sectional study
}

\begin{abstract}
Objectives: To determine the incidence and types of vaginitis in pregnant women at early third trimester and the impact of vaginitis on pregnancy outcome.

Patients and methods: Pregnant women at early third trimester (28-32 weeks) attending for antenatal care unit were evaluated by history, examinations, and ultrasound for fetal assessment. Vaginal swabs were taken from posterior fornix for bacteriological and parasitological examination to determine nature and type of vaginitis. Patients either with evident vaginitis (Group I) or without vaginitis (Group II) were followed up till delivery. Neonatal problems were also assessed.
\end{abstract}

Results: The incidence of vaginitis at Tanta University hospitals was $51.57 \%$. The incidence is more in patients with low education, non-occupied and those from rural areas. Bacterial vaginitis was the most common type (30.63\%). Preterm labour occurred in $33(16.75 \%)$ in vaginitis group compared to $10(11.76 \%)$ in no vaginitis group. PROM occurred 60 (30.46\%) in vaginitis group while occurred in $15(17.67 \%)$ in no vaginitis group.

Conclusion: Vaginitis has a greater incidence in pregnant women attending antenatal care at Tanta University hospitals and is linked to some undesired outcomes. Treatment of vaginitis in pregnancy should be advice to reduce these poor outcomes.

Keywords: Incidence, vaginitis, pregnancy, outcomes
Volume 5 Issue 2 - 2019

\author{
Ayman S Dawood, Mona K Omar \\ Lecturer of Obstetrics \&Gynecology, Faculty of Medicine, Tanta \\ University, Egypt
}

\begin{abstract}
Correspondence: Ayman Shehata Dawood, Tanta University, Faculty of Medicine, Department of Obstetrics and Gynecology, Tanta, Egypt, Tel +201020972067,

Emailayman.dawood@med.tanta.edu.eg
\end{abstract}

Received: March 13, 2019 | Published: April 10, 2019

\section{Introduction}

The incidence of vaginitis during pregnancy increases more and more due to the physiological changes in pregnancy. These changes include high levels of estrogen and progesterone hormones, lowering of immunity of pregnant women, alteration of vaginal microbiome, increased glycogen storage in vaginal cells and alteration in vaginal $\mathrm{PH}$. Moreover poor hygiene, use of vaginal douching and sexual contact all predispose to the high incidence of vaginitis during pregnancy. ${ }^{1,2}$

These changes result in congestion and hypertrophy of vaginal mucosa, which consequently allow more growth of anaerobic bacteria and other pathogenic microorganisms within the vagina. ${ }^{3,4}$ Moreover, there are hypertrophy of cervical gland and proliferation of cervical cells which in turn decreases in B lymphocyte numbers and reduces the local resistance of cervix and vagina to infectious agents. ${ }^{5,6}$ Vaginitis has other causes, such as allergic vaginitis to vaginal sprays, douches, spermicides, soaps, detergents, and fabric softeners. These products can cause burning, itching, and discharge, even if there is no infection. Vaginitis may be due to foreign bodies as pessary or may be of mixed etiologies at the same time. ${ }^{7}$ Increasing opportunities of infection lead to inflammation in the vagina and cervix, therefore increasing the risk of fetal or neonatal morbidity and higher perinatal mortality. ${ }^{8,9}$

Vaginitis or inflammation leads to release of inflammatory mediators consequence of the activation of neutrophils provoking an increase in defensins principally IL-8 in amniotic fluid. ${ }^{10}$ This will share in the pathogenesis of preterm labour with its poor sequalae or by causing premature rupture of membranes (PROM) with congenital fetal and maternal infections. Prematurity may lead to a number of health challenges, including low birth weight. ${ }^{11,12}$ Also vertical transmission of vaginitis inducing microorganisms may lead to severe respiratory problems in new born infants..$^{12}$ This study is designed to estimate incidence of vaginitis in pregnancy and the effects of vaginitis on the outcomes of pregnancy in the enrolled patients.

\section{Patients and methods}

Study design and settings: A cross sectional study. This study was conducted at Obstetrics and Gynecology, Microbiology and Medical Parasitology Departments of Tanta University, in the period from January, 1, 2017 to December, 31, 2018.

Patients: The enrolled patients were selected from the antenatal unit of Department of Obstetrics and Gynecology, Tanta University. Patients were selected according to inclusion and exclusion criteria The inclusion criteria were: (i) pregnant women at early third trimester 28-32 weeks, (ii) singleton living baby, (iii) patients with normal BMI (iv) patients with no previous treatment of vaginitis in current pregnancy. The exclusion criteria were: (i) patient carrying malformed or dead baby, (ii) patients receiving local or systemic treatments for vaginitis in the current pregnancy, (iii) patients with pregestational or gestational diabetes mellitus, (iv) anemic patients, 
(v) patients with history of vaginal bleeding in the preceding two weeks, (vi) patients with vaginal pessary during current pregnancy, and (vii) patients under steroid or antibiotic therapy.

Procedures: All patients were examined in the lithotomy position with good light illumination and under complete aseptic techniques.

Specimen collection: A sterile speculum was introduced to visualize the posterior fornix. Three high vaginal swabs (HVS) were taken and sent to Clinical Pathology Department for detection of any infection and determining the causative organism.

Bacteriological examination: The first swab was examined by naked eye for color, viscosity, and odor. The second swab was utilized in microscopic examination after addition of a drop of $0.9 \%$ saline using both low (10x) and high (40x) power. A drop of $10 \% \mathrm{KOH}$ was added to the slide to assess presence of pseudohyphae or yeast. Addition of $10 \% \mathrm{KOH}$ may yield fishy odor. Vaginal $\mathrm{pH}$ to be assessed also in this smear.

Parasitological examination: The third swab was kept moist by immediate immersion in phosphate-buffered saline to be examined for trichomonas vaginalis. The swab was examined microscopically 20 fields under $400 \mathrm{x}$ magnifications to detect active organism.

\section{Methods}

After Clinical Pathology results, patients were divided into 2 groups, group I with vaginitis and group II without vaginitis. Follow up of patients in both groups were conducted till delivery. Recording of abnormal events as preterm labour or PROM, gestational age at delivery, mode of delivery and assessment of neonatal conditions as weight, congenital infections, respiratory problems and need for incubation were done.

\section{Ethical considerations}

Before starting the study, an approval from the local Ethical Committee of Faculty of Medicine, Tanta University was obtained. All aspects of this study were completely explained for all patients and a written informed consent was taken from them before beginning of the study.

\section{Statistical analysis}

Statistical analysis will be done using SPSS program, version 20 . Percentages, and $\chi^{2}$ (chi square) test are used for qualitative data. Mean \pm SD (Standard Deviation), t-test used for quantitative data. $\mathrm{P}<$ 0.05 is considered significant.

\section{Results}

A total of 430 patients were recruited in this study. Forty eight patients were excluded either not meeting inclusion criteria $(n=41)$ or refusing to participate $(n=7)$. The flow of cases throughout the current study is illustrated in Figure 1. The demographic data of enrolled patients $(n=382)$ was demonstrated in Table 1 . The majority of patients were from rural areas $(64.14 \%)$, of lower educational level (50.78\%), non-occupied (61.78\%), Muslims (84.55\%). Regarding presentations of patients, most of them were symptomatic $(63.35 \%)$. The main symptoms were vaginal discharge, pruritus, dyspareunia and vaginal soreness.

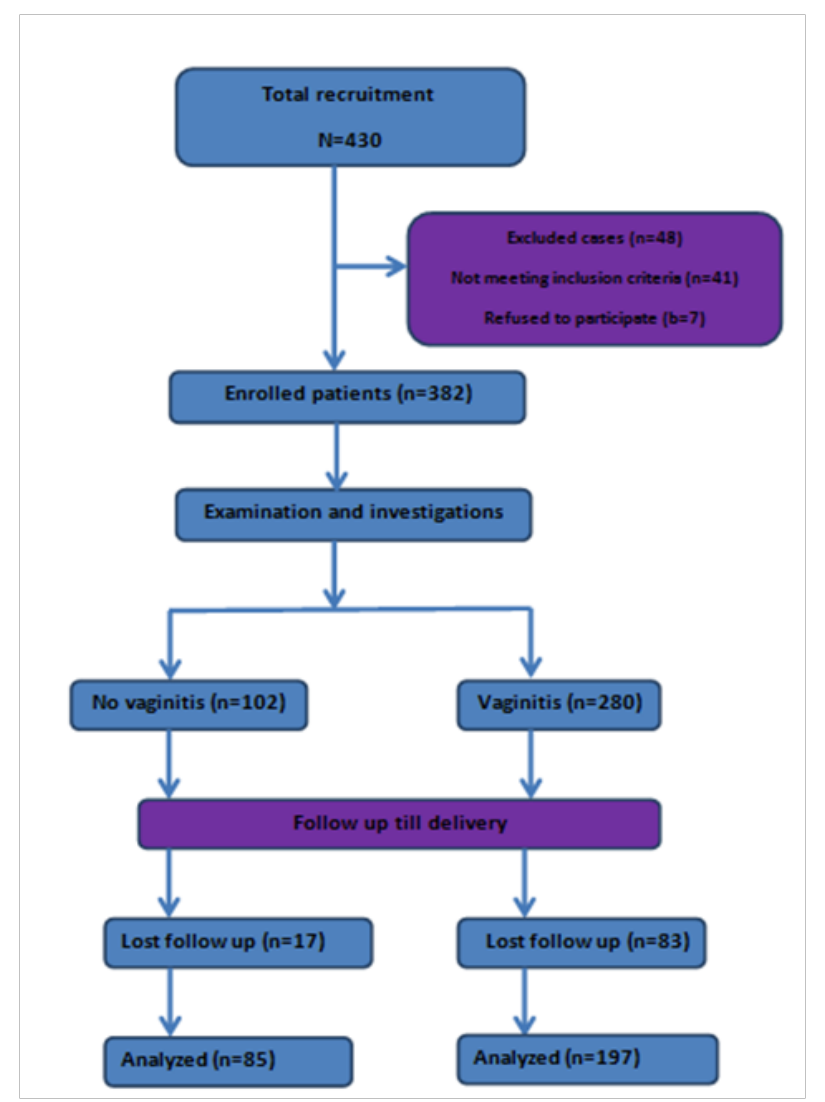

Figure I Flow of cases throughout the current study

The incidence of vaginitis in the enrolled patients was $51.57 \%$. The most frequently met type was bacterial vaginitis (117/197), followed by fungal vaginitis $(62 / 117)$ and lastly parasitic or Trichomonas vaginitis (18/197) as shown in Figure 2. The organisms detected in the enrolled patients were demonstrated in Table 2. The relations of demographic data to incidence of vaginitis are presented in Table 3. There is significant difference in gestational age at delivery between vaginitis and no vaginitis group where gestational age in vaginitis group was $36.48 \pm 1.23$ weeks and in no vaginitis group was $37.11 \pm 2.29$ weeks. The incidence of preterm labour was $33(16.75 \%)$ in vaginitis group while it was $11.76 \%$ in no vaginitis group. PROM was noticed in $60(30.46 \%)$ in vaginitis group while occurred in $15(17.67 \%)$ in no vaginitis group.. Other outcomes are presented in table 4.

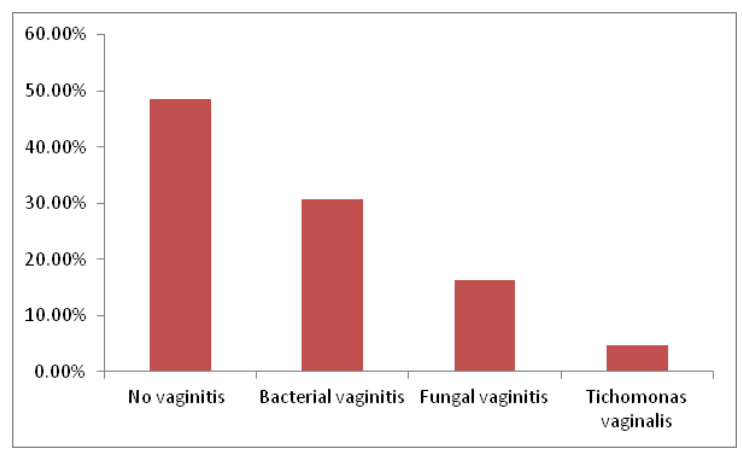

Figure 2 Incidence and types of vaginitis in the current study. 
Table 1 Characteristics of enrolled patients in the current study $(n=382)$

\begin{tabular}{|c|c|c|c|}
\hline & Mean & \pm & SD \\
\hline Age (years) & 29.92 & \pm & 4.56 \\
\hline Gravidity & 3.44 & \pm & 2.13 \\
\hline Parity & 2.71 & \pm & 0.45 \\
\hline BMI & 23.62 & \pm & 2.02 \\
\hline $\begin{array}{l}\text { Gestational age at initial visit } \\
\text { (weeks) }\end{array}$ & 30.47 & \pm & 1.18 \\
\hline \multicolumn{4}{|l|}{ Residence (n,\%) } \\
\hline Urban & 137 & $35.86 \%$ & \\
\hline Rural & 245 & $64.14 \%$ & \\
\hline \multicolumn{4}{|l|}{ Educational level (n,\%) } \\
\hline Non-educated & 88 & $23.04 \%$ & \\
\hline Lower Education & 194 & $50.78 \%$ & \\
\hline Higher Education & 100 & $26.18 \%$ & \\
\hline \multicolumn{4}{|l|}{ Occupation (n,\%) } \\
\hline Non-occupied & 236 & $61.78 \%$ & \\
\hline Occupied & 146 & $38.22 \%$ & \\
\hline \multicolumn{4}{|l|}{ Religion (n,\%) } \\
\hline Muslims & 323 & $84.55 \%$ & \\
\hline Christians & 59 & $15.45 \%$ & \\
\hline \multicolumn{4}{|l|}{ Symptoms of vaginitis $(n, \%)$} \\
\hline Asymptomatic & 140 & $36.65 \%$ & \\
\hline Symptomatic & 242 & $63.35 \%$ & \\
\hline
\end{tabular}

Table 2 Incidence and types of vaginitis in the current study $(n=382)$

\begin{tabular}{lll}
\hline & Number & Percentage (\%) \\
\hline No vaginitis & 185 & $48.43 \%$ \\
Vaginitis & 197 & $51.57 \%$ \\
Bacterial vaginitis & 117 & $30.63 \%$ \\
Bacterial vaginosis & 77 & $20.16 \%$ \\
Chlamydia trachomatis & 12 & $3.14 \%$ \\
Staph.Aureus & 7 & $1.83 \%$ \\
Streptococcus species & 13 & $3.40 \%$ \\
$\begin{array}{l}\text { Escherichia coli } \\
\text { Fungal vaginitis }\end{array}$ & 8 & $2.09 \%$ \\
$\begin{array}{l}\text { Parasitic vaginitis } \\
\text { (Tichomonas vaginalis) }\end{array}$ & 18 & $16.23 \%$ \\
\hline
\end{tabular}

Table 3 The relation of demographic data to incidence of vaginitis

\begin{tabular}{lc}
\hline Parameter & Percentage \\
\hline $\begin{array}{l}\text { Residence } \\
\text { Rrban }\end{array}$ & $12.36 \%$ \\
Rural & $87.64 \%$ \\
Educational level & \\
Non-educated & $73.79 \%$ \\
Lower Education & $16.08 \%$ \\
Higher Education & $10.13 \%$ \\
Occupation & \\
Non-occupied & $81.72 \%$ \\
Occupied & $18.28 \%$ \\
Religion & \\
Muslims & $64.15 \%$ \\
Christians & $35.85 \%$ \\
\hline
\end{tabular}

Table 4 Follow up results of the enrolled patients $(n=300)$

\begin{tabular}{|c|c|c|c|c|}
\hline & $\begin{array}{l}\text { Vaginitis } \\
\text { group } \\
(n=197)\end{array}$ & $\begin{array}{l}\text { No } \\
\text { vaginitis } \\
\text { group } \\
(n=85)\end{array}$ & T-test & P-value \\
\hline Gestation at term & $36.48 \pm 1.23$ & $37.11 \pm 2.29$ & 3.070 & $0.002 *$ \\
\hline $\begin{array}{l}\text { Adverse pregnancy } \\
\text { outcomes } \\
\text { No adverse } \\
\text { outcomes }\end{array}$ & 104 (52.79\%) & $60(70.59 \%)$ & 4.881 & $0.027 *$ \\
\hline Preterm labour & $33(16.75 \%)$ & 10 (1 I.76\%) & 0.637 & 0.424 \\
\hline PROM & 60 (30.46\%) & 15 (I7.67\%) & 3.395 & $0.065 *$ \\
\hline \multicolumn{5}{|l|}{ Mode of delivery } \\
\hline Vaginal & 7I (36.04\%) & 30 (35.29\%) & & \\
\hline Cesarean & $126(63.96 \%)$ & 55 (64.7I\%) & 0.140 & 0.708 \\
\hline $\begin{array}{l}\text { Neonatal birth } \\
\text { weight (gm) }\end{array}$ & $2982.5 \pm 208.8$ & $3007 \pm 215.6$ & & \\
\hline \multicolumn{5}{|l|}{ Neonatal morbidity } \\
\hline No morbidity & I 37 (69.54\%) & 7I (83.53\%) & 4.276 & $0.038 *$ \\
\hline $\begin{array}{l}\text { Respiratory } \\
\text { morbidities }\end{array}$ & 27 (13.7I\%) & $4(4.7 \mid \%)$ & 4.037 & $0.044^{*}$ \\
\hline $\begin{array}{l}\text { Congenital } \\
\text { pneumonia }\end{array}$ & $33(16.75 \%)$ & 10 (11.76\%) & 2.637 & $0.024 *$ \\
\hline Neonatal mortality & $3(1.52 \%)$ & I (I.I8\%) & 0.022 & $0.88 I$ \\
\hline Puerperal fever & 67 (34.01\%) & $22(25.88 \%)$ & 0.811 & 0.367 \\
\hline
\end{tabular}

PROM, Premature rupture of membranes; *, significant p-value.

\section{Discussion}

Vaginitis during pregnancy is common finding due to the low immunity of pregnant women and the high glucose levels in blood that enhance bacterial growth and multiplications..$^{13}$ In the current study we 
found that $51.57 \%$ of patients had vaginitis. The incidence of bacterial vaginitis at Tanta University hospital was found to be $30.63 \%$ where the most common organism was found to be Gardnenrella vaginalis $(20.16 \%)$ as shown in Table 2. The greater incidence was in rural areas denoting poor hygiene and lack of good medical care. On the same side more infections were noted in low educated people $73.79 \%$. The incidence was higher in non-occupied people $(81.72 \%)$ as shown in Table 3.

Follow up of cases led to the detection that vaginitis patient had delivered earlier than patients in no vaginitis group ( $\mathrm{p}$-value $=0.002 *$ ). The most common complications occurred were preterm labour and premature rupture of membranes (PROM) and puerperal fever. Neonatal morbidity and mortality were more in vaginitis group owing to the large number of patients and the more occurrence of preterm labour either spontaneously or complicating PROM cases as shown in Table 4 .

Swadpanich et al., ${ }^{14}$ conducted an intervention review to assess the effectiveness and complications of lower genital tract infection screening and treatment programs in reducing preterm birth and subsequent morbidity. They found that screening and treatment of genital infection programs in pregnant women reduced preterm birth and complications related to prematurity. ${ }^{14}$ Klein \& Gibbs ${ }^{15}$ conducted a study to evaluate whether routine antepartum treatment of lower genital tract infection reduces the incidence of preterm birth in patients with bacterial vaiginitis. They concluded that large trials stated that the routine administration of antibiotics is not beneficial if membranes are intact.

\section{Conclusion}

The incidence of vaginitis at Tanta University hospitals were found to be high as $51.57 \%$ and was found to be linked to pretrm labour, PROm and maternal puerperal fever. Although No significant differences were found between vaginitis and no vaginitis groups in poor outcomes, we recommend treatment of cases with vaginitis to reduce poor outcomes during and after delivery.

\section{Acknowledgments}

We want to thank teams of residents of Obstetrics and Gynecology Department for their efforts and great cooperation in the current study.

\section{Conflicts of interest}

No conflicts to declare.

\section{References}

1. Anderson BL, Mendez-Figueroa H, Dahlke JD, et al. Pregnancy-induced changes in immune protection of the genital tract: defining normal. Am $J$ Obstet Gynecol. 2013;208(4):321.
2. Ghartey JP, Carpenter C, Gialanella P, et al. Association of bactericidal activity of genital tract secretions with Escherichia coli colonization in pregnancy. Am J Obstet Gynecol. 2012;207(4):297.

3. Galiñanes S, Coppolillo E, Cifarelli M, et al. Vaginal inflammatory status in pregnant women with normal and pathogenic microbiota in lower genital tract. ISRN Obstet Gynecol. 2011:835926.

4. Martius J, Eschenbach DA. The role of bacterial vaginosis as a cause of amniotic fluid infection, chorioamnionitis and prematurity--a review. Arch Gynecol Obstet. 1990;247(1):1-13.

5. Srinivasan S, Morgan MT, Liu C, et al. More than meets the eye: associations of vaginal bacteria with gram stain morphotypes using molecular phylogenetic analysis. PLoS One. 2013;8(10):e78633.

6. Fooladi AAI, Khani S, Hosseini HM, et al. Impact of altered early infant gut microbiota following breastfeeding and delivery mode on allergic diseases. Inflamm Allergy Drug Targets. 2013;12(6):410-418.

7. Wen A, Srinivasan U, Goldberg D, et al. Selected vaginal bacteria and risk of preterm birth: an ecological perspective. J Infect Dis. 2014;209(7):10871094.

8. Africander D, Louw R, Verhoog $\mathrm{N}$, et al. Differential regulation of endogenous pro-inflammatory cytokine genes by medroxyprogesterone acetate and norethisterone acetate in cell lines of the female genital tract. Contraception. 2011;84(4):423-435.

9. Simhan HN, Anderson BA, Krohn MA, et al. Trichomonas vaginalis infection in pregnancy. American J Obstetrics Gynecol. 2007;196:e1-5.

10. Centers for Disease Control and Prevention. Genital/vulvovaginal candidiasis statistics. 2012

11. Sutton M, Sternberg M, Koumans EH, et al. The prevalence of Trichomonas vaginalis infection among reproductive-age women in the United States, 2001-2004. Clin Infect Dis. 2007;45:1319-1326.

12. Donbraye E, Donbraye-Emmanuel OOB, Okonko IO, et al. Detection and Prevalence of Trichomonas vaginalis among Pregnant Women in Ibadan, Southwestern Nigeria. World Applied Sciences Journal. 2010;11:15121517.

13. Donati L, Di Vico A, Nucci M, et al. Vaginal microbial flora and outcome of pregnancy. Arch Gynecol Obstet. 2010;281:589.

14. Sangkomkamhang US, Lumbiganon $\mathrm{P}$, Prasertcharoensook W, et al. Antenatal lower genital tract infection screening and treatment programs for preventing preterm delivery. Cochrane Database of System Rev. 2008;2:CD006178.

15. Klein LL, Gibbs RS. Use of microbial cultures and antibiotics in the prevention of infection-associated preterm birth. American journal of obstetrics and gynaecology. 2004;190(6):1493-1502. 